\title{
Spontaneous pneumomediastinum mimicking acute pericarditis
}

\author{
Haseeb Chaudhary ${ }^{1}$, Zohaib Yousaf ${ }^{2}$, Usama Nasir ${ }^{1}$, Tayyab Waheed ${ }^{1}$, and Khezar Syed ${ }^{1}$ \\ ${ }^{1}$ Tower Health \\ ${ }^{2}$ Hamad Medical Corporation
}

June 27, 2021

\begin{abstract}
ST-segment changes may provide a clue to the presence of pneumopericardium accompanying SPM. These EKG changes associated with SPM are rare. The management in SPM with concurrent pneumopericardium is mainly supportive. We describe two SP cases with concomitant pneumopericardium that presented with a deceptive clinical spectrum, closely mimicking acute pericarditis.
\end{abstract}

\section{Abbreviations:}

1. electrocardiogram (EKG)

2. spontaneous pneumomediastinum (SPM)

3. Computed tomography (CT)

Spontaneous pneumomediastinum mimicking acute pericarditis

\begin{abstract}
ST-segment changes may provide a clue to the presence of pneumopericardium accompanying SPM. These EKG changes associated with SPM are rare. The management in SPM with concurrent pneumopericardium is mainly supportive. We describe two SP cases with concomitant pneumopericardium that presented with a deceptive clinical spectrum, closely mimicking acute pericarditis.
\end{abstract}

Keywords: Pneumomediastinum, EKG, ST-T wave changes, acute coronary syndrome, acute pericarditis

\section{Key Clinical Message:}

- The atypical clinical presentation of pneumomediastinum may produce EKG changes.

- The EKG changes of pneumomediastinum can mimic acute pericarditis.

- Early recognition and appropriate treatment can lead to improved clinical outcomes.

\section{Introduction:}

ST elevations on EKG have a broad differential diagnosis that can vary from benign to more ominous pathologies. These include early repolarization, coronary vasospasm, acute pericarditis, ST-elevation myocardial infarction, ventricular aneurysms, and dissecting aneurysm of the aorta reaching the pericardium. (1-50 The presentation of these diseases can closely resemble SPM, in which patients often present with sudden onset chest pain and shortness of breath. Furthermore, the clinical scenario in patients with underlying SPM can pose a diagnostic challenge due to ST-T changes on EKG that may mimic acute coronary syndrome. (6-8) These EKG changes associated with SPM have seldom been reported in the literature. We describe two SP cases with concomitant pneumopericardium that closely mimics acute pericarditis with a deceptive clinical spectrum. 


\section{Case presentation:}

Patient characteristics are summarized in Table 1

\section{Case 1.}

A 19-year-old gentleman with a history of occasional marijuana use presented with acute onset progressive central and sharp chest pain for several hours, followed by a brief syncopal episode. The pain was pleuritic and exacerbated on lying flat. He denied any trauma, fever, cough, retching, or vomiting. He did not have any previous history of hospitalizations. On presentation, the blood pressure was $117 / 79 \mathrm{mmHg}$ with a pulse rate of 76 beats/min, temperature $37.7{ }^{\circ} \mathrm{C}\left(99.9{ }^{\circ} \mathrm{F}\right)$, and a respiratory rate of 22 breaths/min with an oxygen saturation of $96 \%$ on ambient air. He did not have orthostasis. There was crepitus around the left lower neck, appreciated on palpation, and precordial auscultation was significant for a Hamman's crunch best heard in the $4^{\text {th }}$ left intercostal space suggestive of subcutaneous emphysema. Complete blood counts $(\mathrm{CBC})$ revealed a white cell count (WBC) of $5.4 \times 10^{3}, \mathrm{Hb} 15 \mathrm{~g} / \mathrm{dl}$, platelets $241 \times 10^{3}$ per microlitre. EKG showed ST-segment elevations in the precordial leads (Figure 1a). Serial troponins were negative. Chest X-ray revealed a continuous diaphragm sign suggestive of pneumomediastinum, which was confirmed by computed tomography (CT) of the chest showing evidence of spontaneous pneumomediastinum along with pneumopericardium (Figure 2a). The echocardiogram was unremarkable. An esophagram was not performed given the low suspicion for any esophageal rupture. The patient was successfully managed with mild analgesia, oxygen therapy, and clinical observation, with gradual resolution of EKG changes as the pneumopericardium resolved.

\section{Case 2.}

A 19-year-old gentleman with a history of smoking and marijuana use presented with left-sided chest pain, proceeded by intractable nausea and vomiting for two weeks. The pain radiated to the neck, upper back, and shoulders base and was not associated with shortness of breath. He did not report hematemesis or melena. He denied upper respiratory tract symptoms. On presentation, his blood pressure was 162/91 $\mathrm{mmHg}$, pulse rate of $82 / \mathrm{min}$, temperature $36.7^{\circ} \mathrm{C}\left(98.1{ }^{\circ} \mathrm{F}\right)$, and oxygen saturation of $98 \%$ on ambient air. He had supraclavicular crepitus but otherwise normal systemic examination. CBC showed WBC count of $7.10 \times 10^{3}$ per microlitre., $13.8 \mathrm{~g} / \mathrm{dl}, 214 \times 10^{3}$ per microlitre. EKG showed diffuse ST-segment elevation, PR segment depression, and evidence of left ventricular hypertrophy, with no reciprocal changes suggestive of acute pericarditis(Figure 1b). Chest X-ray showed pneumomediastinum. A subsequent CT chest showed air in the anterior mediastinum, pneumopericardium, and subcutaneous emphysema (Figure 2b).Esophagram did not show any evidence of a leak. The patient was initially started on ibuprofen and colchicine given the EKG changes highly suggestive of acute pericarditis, but later therapy was tailored to mild analgesia with clinical observation. EKG changes subsided upon resolution of pneumo-pericardium.

\section{Discussion:}

Pneumomediastinum relates to the accumulation of air in the mediastinal structures. It may result from blunt trauma leading to thoracic injury, esophageal perforation, or hollow viscus rupture. It can also occur spontaneously without any structural lung or mediastinal abnormalities in the absence of trauma, called SPM. In general, SPM can be caused by intrathoracic (involving trachea and major bronchial airways, esophagus, lung, and pleural cavity) or extra-thoracic (head, neck, or peritoneum) processes. SPM is a non-traumatic entity that occurs due to increased intrathoracic pressure leading to alveolar rupture. As the mediastinal pressure is more negative than the pulmonary parenchyma, the air enters the pulmonary interstitium. It dissects along the perivascular sheets to reach the hilum from where it spreads to the mediastinum. This phenomenon is described as the Macklin effect.(9) Occasionally, pneumopericardium can also occur with leakage of air into the pericardial space. (10) It is worth emphasizing, spontaneous alveolar rupture can occur even with no prior history of pulmonary disease or esophageal perforation and is usually precipitated by cough, emesis, physical exercise, labor, or upper airway infection.

The exact mechanism of ST-segment changes secondary to SPM remains unclear. The most common EKG 
findings associated with SPM are the loss of R wave in the precordial leads and diminution of QRS voltages or ST-segment elevation in inferior leads (11-15). Previously described mechanisms propose cardiac rotation, right ventricular dilatation, and insulation effect caused by air accumulation between the cardiac structures and the chest wall as the cause of such changes. Secondly, SPM may lead to myocardial stretch leading to stretching and narrowing of the coronary arteries, which may masquerade as ST-elevation myocardial infarction with a troponin leak (15). We further postulate the EKG changes associated with pneumopericardium in our cases could be related to the direct inflammatory effect from air leakage between the pericardium and the chest wall leading to a presentation similar to acute pericarditis. Such ST-T changes may give an initial diagnostic clue of the presence of pneumopericardium accompanying SPM. The concurrent pneumopericardium diagnosis may be relevant if caused by fistula formation from the adjacent intra-abdominal structures as mortality rates can be as high as 50-70\% in such cases. $(\mathbf{1 6}, \mathbf{1 7})$ Given the lack of abdominal symptoms and CT findings not suggestive of an intra-abdominal or esophageal source in Case 1, an esophagram was not performed. The esophagram in the second described case was performed as the patient presented with hyperemesis, leading to Boerhaave syndrome suspicion. These patients appear sicker on presentation with hypotension and shock due to chemical mediastinitis, and a pleural effusion often accompanies findings of SPM. (18)

Management of SPM is mainly conservative with avoidance of trigger factors, analgesia, bed rest, and oxygen therapy in the absence of complications such as hemodynamic instability, pneumothorax, suspected chemical mediastinitis, or tamponade effect by the coexisting pneumopericardium.

\section{Conclusion:}

Our cases highlight the association of ST-segment elevation with SPM that may mimic acute pericarditis. This can pose a diagnostic challenge for clinicians and lead to unnecessary investigations and pharmacotherapy. Although the presentation can be dramatic, aggressive management is seldom required in these patients, even in the presence of a concurrent pneumopericardium without tamponade physiology.

Tables and figures:

Table 1. Patient Characteristics (EKG-electrocardiogram; CT- Computed tomography)

\begin{tabular}{|c|c|c|}
\hline$\overline{\text { Patient Characteristics }}$ & Case 1 & Case 2 \\
\hline$\overline{\text { Age }}$ & 19 years & 19 years \\
\hline Sex & Male & Male \\
\hline Risk Factors & $\begin{array}{l}\text { Occasional marijuana use, } \\
\text { Smoking }\end{array}$ & Marijuana use, Vaping \\
\hline Symptoms & $\begin{array}{l}\text { Chest pain, shortness of breath, } \\
\text { syncope }\end{array}$ & Hyperemesis, Chest pain \\
\hline CRP & $0.11(<1.00 \mathrm{mg} / \mathrm{dl})$ & $0.50(<1.00 \mathrm{mg} / \mathrm{dl})$ \\
\hline Troponin & $0.03(<0.06 \mathrm{ng} / \mathrm{ml}) \times 2$ & $0.03(0.06 \mathrm{ng} / \mathrm{ml}) \times 2$ \\
\hline EKG changes & $\begin{array}{l}\text { ST-T elevations V3-V4 with PR } \\
\text { depression in AVR }\end{array}$ & $\begin{array}{l}\text { Diffuse ST-T elevations with } \\
\text { PR depression in AVR with } \\
\text { evidence of LVH }\end{array}$ \\
\hline Chest Xray & $\begin{array}{l}\text { Subcutaneous emphysema, } \\
\text { continuous diaphragm sign }\end{array}$ & $\begin{array}{l}\text { The air along the mediastinum } \\
\text { and subcutaneous emphysema }\end{array}$ \\
\hline CT Findings & $\begin{array}{l}\text { Subcutaneous emphysema, } \\
\text { moderate pneumomediastinum } \\
\text { with pneumopericardium, and a } \\
\text { collapsed esophagus }\end{array}$ & $\begin{array}{l}\text { Subcutaneous emphysema, } \\
\text { moderate pneumomediastinum, } \\
\text { pneumopericardium, esophagus } \\
\text { not well visualized. }\end{array}$ \\
\hline
\end{tabular}




\begin{tabular}{|c|c|c|}
\hline Patient Characteristics & Case 1 & Case 2 \\
\hline Echocardiogram & $\begin{array}{l}\text { Normal function, no evidence of } \\
\text { pericardial effusion. }\end{array}$ & $\begin{array}{l}\text { Mild concentric left ventricular } \\
\text { hypertrophy normal chamber size } \\
\text { and hyperdynamic systolic } \\
\text { function with no apparent } \\
\text { regional wall motion } \\
\text { abnormalities. }\end{array}$ \\
\hline Esophagram & Not performed & $\begin{array}{l}\text { No evidence of an esophageal } \\
\text { leak }\end{array}$ \\
\hline
\end{tabular}

Figure 1. EKG demonstrating (a) ST-T elevations V3-V4 with PR depression in AVR (b) Diffuse ST-T elevations with PR depression in AVR with evidence of LVH

Figure 2 . CT Thorax (Coronal View) with (a) Subcutaneous emphysema, Moderate pneumomediastinum with pneumopericardium and a collapsed esophagus (b) Subcutaneous emphysema, Moderate pneumomediastinum, pneumopericardium, esophagus not well visualized.

\section{Acknowledgements:}

Qatar National Library will fund the open access Article processing charges for the publication.

\section{Author contributions:}

Conceptualization: $\mathrm{HC}, \mathrm{KS}$

Patient consent: HC

Literature review: $\mathrm{HC}, \mathrm{KS}, \mathrm{ZY}$

Manuscript writing: $\mathrm{HC}, \mathrm{KS}$

Data collection: $\mathrm{HC}, \mathrm{KS}$

Radiology part in writing and images: KS

Critical review and modifications: $\mathrm{HC}, \mathrm{KS}, \mathrm{ZY}$

Final review and approval: $\mathrm{HC}, \mathrm{KS}, \mathrm{UN}, \mathrm{TW}, \mathrm{ZY}$.

\section{References:}

1.Bhardwaj R, Berzingi C, Miller C, Hobbs G, Gharib W, Beto RJ, Warden BE, Jain AC. Differential diagnosis of acute pericarditis from normal variant early repolarization and left ventricular hypertrophy with early repolarization: an electrocardiographic study. Am J Med Sci. 2013 Jan;345(1):28-32. doi: 10.1097/MAJ.0b013e3182541d6d. PMID: 22814363.

2.Early repolarization. Differential diagnosis of electrocardiographic ST-segment elevation]. Ugeskr Laeger. 2000 Oct 30;162(44):5914-7. Danish. PMID: 11094551.

3.de Bliek EC. ST-elevation: Differential diagnosis and caveats. A comprehensive review to help distinguish ST-elevation myocardial infarction from nonischemic etiologies of ST elevation. Turk J Emerg Med. 2018 Feb 17;18(1):1-10. doi: 10.1016/j.tjem.2018.01.008. PMID: 29942875; PMCID: PMC6009807.

4-Brady W.: ST-segment elevation in ED adult chest pain patients: etiology and diagnostic accuracy for AMI. J Emerg Med 1998; 16: pp. 797-798.

5.Chenkin J. Diagnosis of Aortic Dissection Presenting as ST-Elevation Myocardial Infarction using PointOf-Care Ultrasound. J Emerg Med. 2017 Dec;53(6):880-884. doi: 10.1016/j.jemermed.2017.08.012. Epub 2017 Oct 20. PMID: 29066079. 
6. Brearley W.D., Lee T., Haley M.W., Littmann L.: Pneumomediastinum mimicking acute ST-segment elevation myocardial infarction. Int J Cardiol 2007; 117: pp. 73-75.

7.Lolay GA, Burchett A, Ziada KM. Pneumomediastinum and ST-Segment Elevation. Am J Cardiol. 2016 Nov 15;118(10):1603-1604. doi: 10.1016/j.amjcard.2016.08.032. Epub 2016 Aug 22. PMID: 27634033.

8.Skaug B, Taylor KR, Chandrasekaran S. Oesophageal rupture masquerading as STEMI. BMJ Case Rep. 2016 Apr 11;2016:10.1136/bcr-2016-214906. doi: 10.1136/bcr-2016-214906. PMID: 27068730; PMCID: PMC4840706.

9. Wintermark M, Schnyder P. The Macklin effect: a frequent etiology for pneumomediastinum in severe blunt chest trauma. Chest. 2001 Aug;120(2):543-7. doi: 10.1378/chest.120.2.543. PMID: 11502656.

10. Vanzo V, Bugin S, Snijders D, Bottecchia L, Storer V, Barbato A. Pneumomediastinum and pneumopericardium in an 11-year-old rugby player: a case report. J Athl Train. 2013 Mar-Apr;48(2):277-81. doi: 10.4085/1062-6050-48.1.11. Epub 2013 Feb 20. PMID: 23672393; PMCID:

PMC3600931.

11.Tse TS, Tsui KL, Yam LY, So LK, Lau AC, Chan KK, Li SK. Occult pneumomediastinum in a SARS patient presenting as recurrent chest pain and acute ECG changes mimicking acute coronary syndrome. Respirology. 2004 Jun;9(2):271-3. doi: 10.1111/j.1440-1843.2004.00569.x. PMID: 15182281

12.Martinez CM, Gaspar ML, Ribes EA, Amenos AM, Prevosti EF, Robert LP. Pneumomediastinum following a surgical renal biopsy. J Urol. 1976 Jul;116(1):94-5. doi: 10.1016/s0022-5347(17)58695-4. PMID: 933301.

13.Zimmerman A, Rafii SE, Strom JA. Subcutaneous emphysema and pneumomediastinum. A cause of low voltage electrocardiogram. Heart Dis.2001; 3: 85-6.

14.Ratnayake EC, Premaratne S, Lokunarangoda N, Fernando S, Fernando N, Ponnamperuma C, Santharaj WS. Pneumopyopericardium mimicking an inferior ST-elevation myocardial infarction with regional electrocardiogram changes: a case report. BMC Res Notes. 2015 Apr 30;8:173. doi: 10.1186/s13104-015-1143-7. PMID: 25924710; PMCID: PMC4417527.

15. Frenkel A, Binyamin Y, Zeldetz V, Koyfman L, Klein M, Brotfain E. Pneumomediastinum, ST elevation and urgent cardiac catheterisation: a crucial triad? BMJ Case Rep. 2019 Feb 6;12(2):e227932. doi: 10.1136/bcr-2018-227932. PMID: 30733249; PMCID: PMC6381960.

16. Vidi, Venkatesan \& Singh, Premranjan \& Alhumaid, Alia \& Lee, Richard \& Kinnunen, Paula. (2009). Hydropneumopericardium presenting as an acute coronary syndrome: A rare complication of paraesophageal hernia. Texas Heart Institute journal / from the Texas Heart Institute of St. Luke's Episcopal Hospital, Texas Children's Hospital. 36. 255-8.

17. Cummings RG, Wesly RL, Adams DH, Lowe JE. Pneumopericardium resulting in cardiac tamponade. Ann Thorac Surg. 1984 Jun;37(6):511-8. doi: 10.1016/s0003-4975(10)61146-0. PMID: 6375601.

18. Light RW. Exudative pleural effusions secondary to gastrointestinal diseases. Clin Chest Med. 1985 Mar;6(1):103-11. PMID: 3847297. 

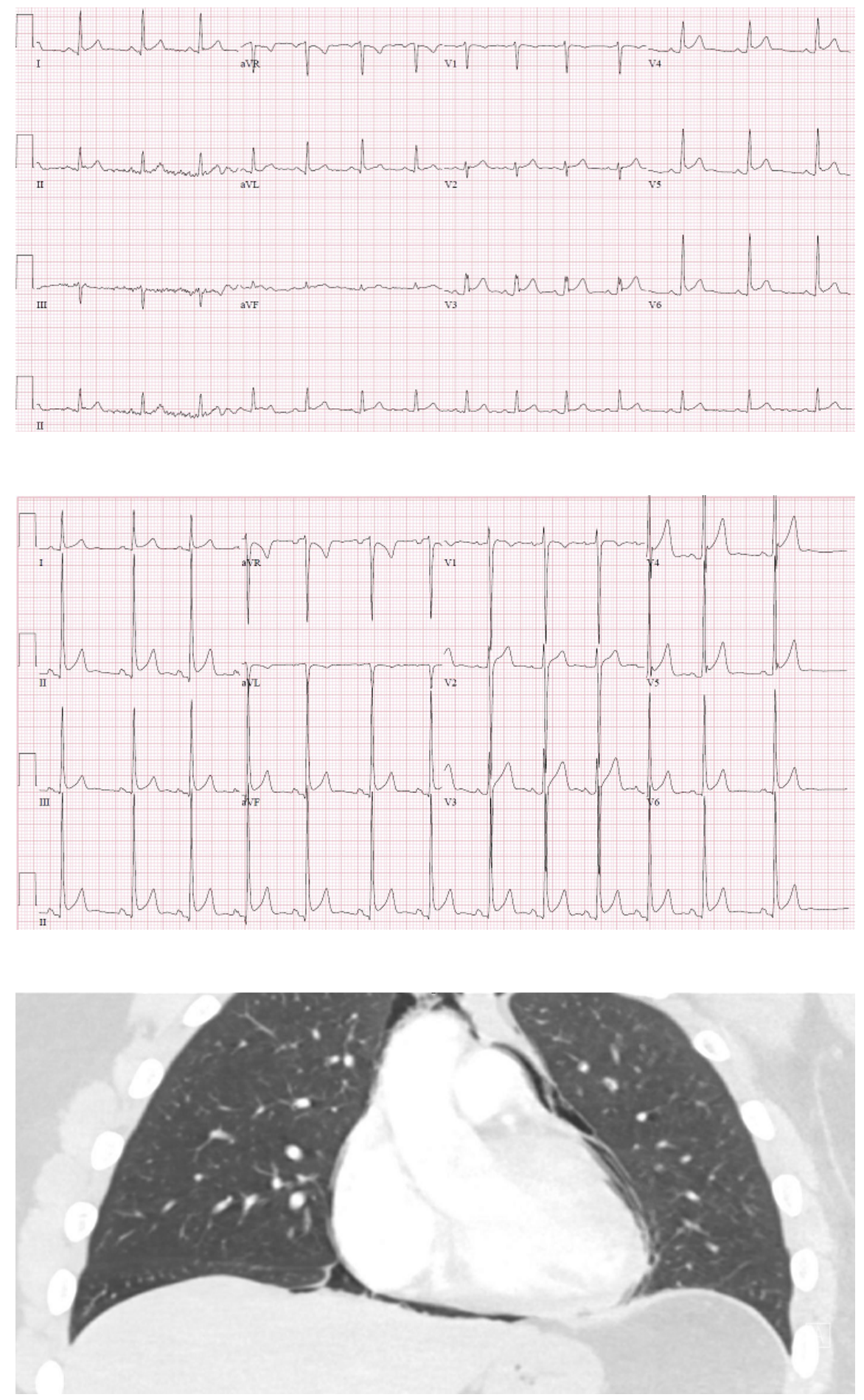


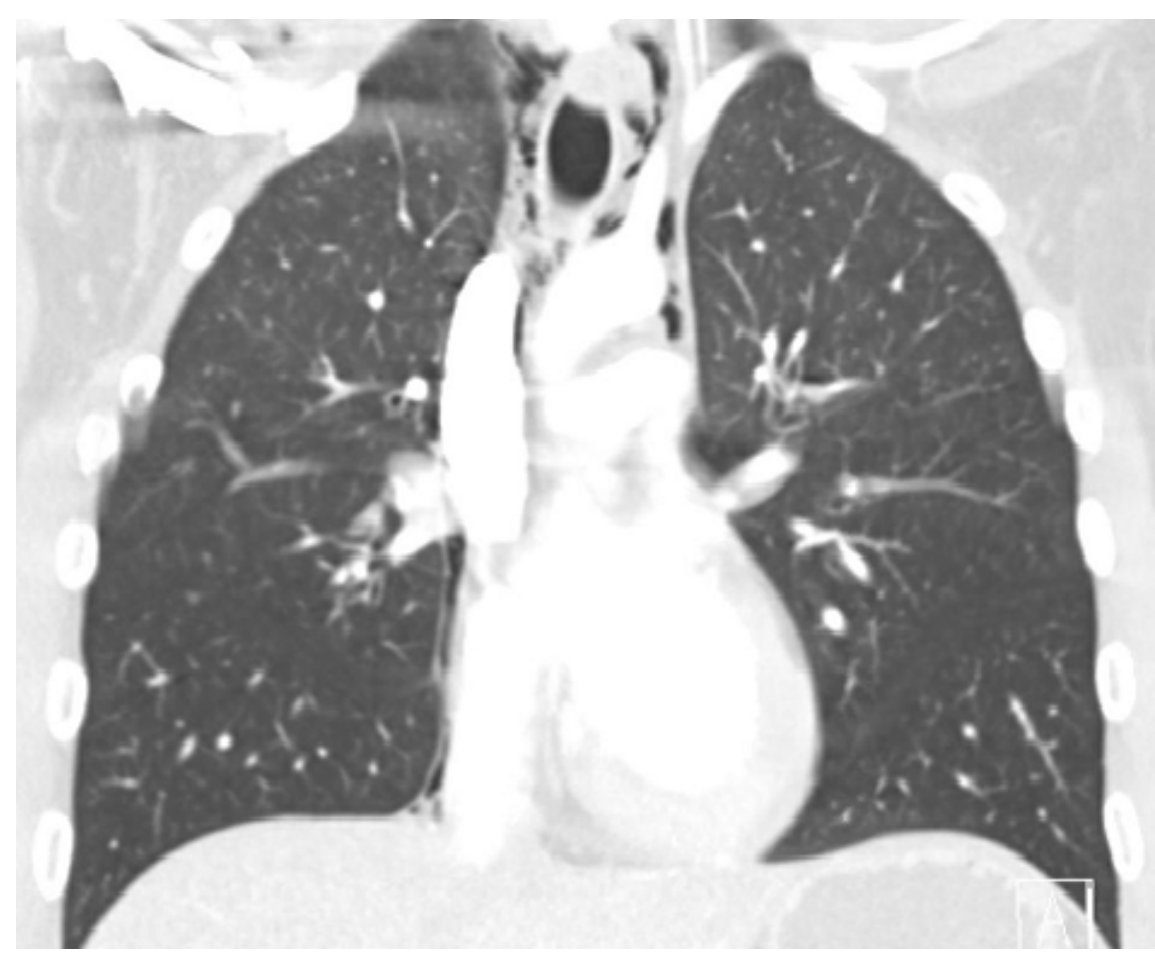

